\title{
La Iglesia y los sacerdotes cubanos ante el régimen constitucional gaditano (1812-1814 y $1820-1823)^{*}$
}

The Church and priests in Cuba under the Constitution of Cadiz (1812-1814 and 1820-1823)

Alain J. SANTOS FUENTES
Universidad del País Vasco (UPV/EHU)
asantos_cu@yahoo.es

Abstract: The Constitution of Cadiz was applied throughout Cuban territory in the two periods in which it was in force, 1812-1814 and 1820-1823, when the island was free from the convulsions of the wars of independence. This paper analyzes the participation of the Cuban ecclesiastical establishment in this process. As the sources reveal, the Cuban clergy, encouraged by the bishop of Havana, was characterized by its involvement at the local level in establishing the representative system. The clergy had a dual role as citizens and representatives of the new State, but were also vocal in defense of local interests against other authorities, and resisted the criticism of the most pro-colonial reactionary faction, especially during the Liberal Triennium.

Keywords: Constitution of Cádiz; clergy; Cuba.
Resumen: La Constitución gaditana se aplicó en todo el territorio cubano en los dos períodos en que estuvo vigente, 1812-1814 y 1820-1823, al quedar libre la isla de las convulsiones de las guerras de independencia. En este trabajo se analiza la participación del estamento eclesiástico cubano en ese proceso. Como revelan las fuentes, el clero cubano, alentado por el prelado de La Habana, se caracterizó por su implicación a nivel local en la erección del sistema representativo, en su doble papel de ciudadanos y representantes del nuevo Estado, pero también en defensa de los intereses locales frente a otras autoridades, a pesar de las críticas que recibió desde la facción más colonialista y reaccionaria, especialmente durante el Trienio liberal.

Palabras clave: Constitución de Cádiz; clero; Cuba.

\section{LA CONSTITUCiÓN DE CÁDIZ, LA RELIGIÓN Y EL CLERO}

La intolerancia religiosa del régimen nacido con la Constitución de Cádiz representa una clara distinción entre el primer constitucionalismo español y sus pares

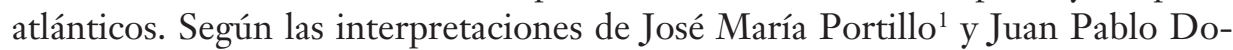

* Este trabajo forma parte de las actividades del Grupo de Investigación del Sistema Universitario Vasco «País Vasco, Europa y América: vínculos y relaciones atlánticas».

1 José María Portillo Valdés, De la Monarquía Católica a la Nación de los Católicos, en Historia y política: Ideas, procesos y movimientos sociales, 17 (2007) (Ejemplar dedicado a: El liberalismo español), pp. 17-35. 
mínguez ${ }^{2}$, la religiosidad y el profundo catolicismo de los constituyentes hispanos explican que no hallasen contradicción alguna en defender un proyecto liberal, basado en los principios de la soberanía nacional, la representación y la libertad de prensa, con la definición de una nación católica y de un gobierno que tenía la obligación de proteger la religión católica romana y garantizar su exclusividad. Un análisis global y sistemático del texto de la carta magna les permite demostrar que el artículo 12, que ha acaparado la atención de historiadores y politólogos ${ }^{3}$, no resulta extravagante en ella y que la intolerancia religiosa atraviesa toda la obra constitucional y la posterior labor legislativa de las Cortes, y constituyó uno de los pilares de la monarquía constitucional gaditana:

Las Cortes se abrieron con un ceremonial religioso, declararon repetidas veces que la guerra contra los franceses era una guerra de religión y no dudaron en suscitar rogativas para resolver los más diversos problemas. La Constitución comenzaba invocando a la Santísima Trinidad, concedía al clero secular un papel privilegiado en los organismos del Estado, establecía las parroquias como base del sistema electoral y exigía el catolicismo como condición indispensable para obtener la ciudadanía española... Los diputados, al reunirse en la Isla de San Fernando, juraron que defenderían «la santa religión católica apostólica romana, sin admitir otra alguna en estos reinos». Los primeros decretos de las Cortes impusieron también ese juramento a todas las autoridades civiles, militares y eclesiásticas del Estado. Y ese mismo juramento debía renovarse anualmente según el artículo 117 de la Constitución. También al rey y al príncipe de Asturias se les obligó constitucionalmente a jurar que protegerían la religión católica, «sin permitir otra alguna en el reino» ${ }^{4}$.

Para Portillo, el artículo 12 representa el punto culminante de una obra muy coherente, diseñada por los «arquitectos» de la Constitución para garantizar la preservación de la soberanía en el tránsito de la monarquía católica a la nación católica, como nuevo sujeto político capaz de encarnarla. La religión católica se convertía así en la argamasa esencial que legitimaba la unidad de la extensa y heterogénea comunidad política que representaba la monarquía hispánica, «en símbolo necesario de españolidad y de ciudadanía española» ${ }^{5}$. La constatación más evidente de esto, según el autor, deriva del papel que otorga la Constitu-

2 Juan Pablo Domínguez, Intolerancia religiosa en las Cortes de Cádiz, en Hispania, vol. LXXVII, 255 (2017), pp. 155-183.

3 «La Religión de la Nación española es y será perpetuamente la católica, apostólica, romana, única verdadera. La nación la protege por leyes sabias y justas, y prohíbe el ejercicio de cualquiera otra».

4 Juan Pablo DomíngueZ, Intolerancia religiosa... [ver n. 2], p. 159

5 José María PORTILlo ValdÉs, De la Monarquía Católica... [ver n. 1], p. 22. 
ción a la vecindad, como categoría básica e indispensable para ser tenido como español y como ciudadano español, una doble categorización sui géneris del texto gaditano, que separaba a los habitantes de los territorios de las Españas entre los únicamente portadores de derechos civiles (los primeros) y los titulares de los derechos políticos (los segundos) ${ }^{6}$.

El artículo 5.1 establecía que serían tenidos por españoles aquellos «hombres libres nacidos y avecindados en los dominios de las Españas» y el 18, que serían considerados ciudadanos «aquellos españoles que por ambas líneas traen su origen de los dominios españoles de ambos hemisferios, y están avecindados en cualquier pueblo de los mismos dominios». Siguiendo el argumento de José María Portillo, la ciudadanía española dependía de dos criterios: el origen en un espacio (el de la monarquía en ambos hemisferios) y la religión católica (explicitado en la centralidad del concepto de vecino). La vecindad, un criterio de profunda raigambre cristiana y medieval, aparecía como requisito indispensable para gozar de cualquiera de los dos niveles de pertenencia a la nación que detallaba la Constitución. En la práctica, la apelación a la vecindad conducía a la parroquia, como estructura primaria del ordenamiento territorial del nuevo régimen, y más específicamente al párroco y a la comunidad de los feligreses como garante del censo electoral. Sólo el acuerdo entre el conjunto de los vecinos, bajo la atenta mirada del cura y el resto de autoridades (si las hubiese), permitiría el ejercicio de los derechos de ciudadanía ${ }^{7}$.

Respecto al papel que los constituyentes reservaron al clero es necesario diferenciar entre regulares y seculares. En línea con la tradición ilustrada, los diputados liberales impulsaron la exclusión de los primeros de los derechos de ciudadanía. En la obra legislativa posterior de las Cortes ordinarias se ahondó en la reforma de los regulares, por motivaciones fundamentalmente hacendísticas, hasta que por real decreto de $25-\mathrm{X}-1820$ se reguló la eliminación de algunas comunidades, la reforma de otras y el destino que tendrían los bienes de las comunidades suprimidas ${ }^{8}$. Al clero secular no solo le reconocieron sus derechos

6 Sobre la sui generis concepción de la ciudadanía en la Pepa, ver: Joaquín VARELA SUANCES, Propiedad, ciudadanía y sufragio en el constitucionalismo español (1810-1845), en Historia Constitucional, 6 (2005); Jaime E. RODRÍGUEZ O., La ciudadanía y la Constitución de Cádiz, en Ivana FrASQUET (coord.), Bastillas, cetros y blasones: la independencia en Iberoamérica, Mapfre, Madrid, 2006, pp. 39-56; Bartolomé Clavero, Constitución de Cádiz y ciudadanía de México, en Carlos Garriga (coord.), Historia y Constitución: trayectos del constitucionalismo bispánico, FCE, Ciudad de México, 2010, pp. 141-172.

7 José María PORTillo ValdÉs, De la Monarquía Católica... [ver n. 1], p. 23.

8 Maximiliano BARRIO, Reforma y supresión de los regulares en España al final del Antiguo Régimen (1759-1836), en Investigaciones Históricas, 20 (2000), pp. 89-118, p. 111. 
como ciudadanos, sino que también le demandaron «un cierto apoyo moral al régimen» ${ }^{9}$. Los curas podrían votar y ser nombrados electores, pero además debían estar presentes en las juntas parroquiales, después de decir una misa del Espíritu Santo y dar un discurso acorde a la circunstancia, entre otras obligaciones que les imponía la Constitución ${ }^{10}$. Tenemos, por tanto, a un clero secular que ejerce sus derechos activos y pasivos como ciudadano, a la vez que se convierte en oficiante de la liturgia del nuevo régimen, tiene un papel determinante en la conformación del cuerpo ciudadano y conserva su dignidad como sacerdote de la única religión tolerada por el Estado.

Si los constituyentes fueron conscientes del papel esencial que jugaba la religión católica como argamasa de la nación trasatlántica, también lo fueron de la necesidad que tenía el nuevo régimen de poner bajo control político a las instituciones eclesiásticas y a los religiosos ${ }^{11}$. Las reformas diseñadas por las Cortes constituyentes no hicieron sino agudizar el enfoque regalista de intervención en la organización eclesiástica y en la disciplina externa de la Iglesia, para lo cual los diputados liberales contaron el inestimable apoyo de una buena parte del clero $^{12}$. Sin embargo, la profundización en la doctrina regalista se hacía con un importante cambio, pues «el antiguo patronato o vicariato deja de ser una prerrogativa del rey para convertirse en un derecho de la nación, o más consecuentemente del congreso o representación nacional» ${ }^{13}$, cuya legislación incluía por primera vez el principio de obediencia y cumplimiento obligatorio. El resultado más relevante de la subordinación de la Iglesia a la soberanía de la

9 Manuel MoRán, Revolución y reforma religiosa en las Cortes de Cádiz, Actas, Madrid, 1994, p. 42.

10 Art. 35: «Las juntas electorales de parroquia se compondrán de todos los ciudadanos avecindados y residentes en el territorio de la parroquia respectiva, entre los que se comprehenden los eclesiásticos seculares». Art. 46: «Las juntas de parroquia serán presididas por el gefe político ó el alcalde de la ciudad, villa ó aldea en que se congregaren, con asistencia del cura párroco para mayor solemnidad del acto...». Art. 47: «Llegada la hora de la reunión [...] hallándose juntos los ciudadanos que hayan concurrido, pasarán á la parroquia con su presidente, y en ella se celebrará una misa solemne de Espíritu Santo por el cura párroco, quien hará un discurso correspondiente á las circunstancias».

11 La paradoja del artículo 12 es que, a la vez que garantizaba la exclusividad de la religión y la Iglesia católica en el territorio español, abría la puerta a la reforma de la Iglesia por parte de los políticos, para adaptarla a los intereses nacionales, y acababa con las vías tradicionales que había encontrado el clero para preservar sus intereses frente a las aspiraciones intervencionistas de la monarquía absolutista.

12 Manuel MoRÁN, Revolución y reforma... [ver n. 9], pp. 43-49.

13 Jorge ADAME, Asimilación y rechazo en México del sistema de relaciones entre la Iglesia y el estado contemplado en la Constitución de Cádiz, en Anuario Mexicano de Historia del Derecho, 22 (2010), pp. 57 74, p. 68. 
nación fue la supresión por decreto de las Cortes del Tribunal del Santo Oficio el 23 de febrero de $1813^{14}$. Como destaca Manuel Morán, estas reformas del clero y de la Iglesia no se produjeron por acuerdo unánime de las Cortes y sí en medio de amplios debates dentro y fuera de los plenarios, especialmente en los medios de prensa. La reacción de los sectores más antiliberales del clero español no se hizo esperar y durante todo el período se sucedieron los enfrentamientos.

\section{CUBA EN TIEMPOS DE CONSTITUCiÓN}

A principios del siglo XIX Cuba se había convertido en una de las posesiones más ricas de la corona española en América tras un acelerado proceso de expansión de la agricultura de exportación. El impulso definitivo hacia la transformación en una colonia de plantación esclavista se produjo tras la revolución haitiana y el descalabro de las producciones azucareras y cafetaleras de los colonos franceses en el Caribe. Hasta las décadas centrales del siglo, puede decirse que el modelo estuvo en pleno proceso de crecimiento, expandiendo los cultivos desde la región habanera hacia el interior de la isla y alterando radicalmente la composición demográfica y el régimen de trabajo. En paralelo a la expansión de las plantaciones de azúcar, café y otros productos de exportación, se fue poblando el territorio por esclavos africanos procedentes de la trata, pero también por inmigrantes blancos de España y América, atraídos por la prosperidad de la isla. La transformación fue protagonizada por un grupo de la élite habanera, que gozó de un trato privilegiado por parte del gobierno de la monarquía, para garantizar un flujo constante de mano de obra esclava y libertad de exportación, a cambio de recursos fiscales. El «pacto colonial» entre la sacarocracia ilustrada y los gobernantes absolutistas garantizó la prosperidad de la colonia, la estabilidad política y la hegemonía de sus protagonistas durante varias décadas ${ }^{15}$.

14 Sobre la abolición del tribunal, ver Beatriz CÁRCELES, Reformalabolición del Tribunal de la Inquisición (1812-1823). La constitución de la autoridad absoluta, en Manuscrits, 17 (1999), pp. 179199. La autora demuestra como el decreto de 23-II-1813 supuso el surgimiento en España de una autoridad absoluta (la nación) que subordinaba todo principio de representación, acabando con el principio tradicional de «se obedece pero no se cumple», que garantizaba la libertad de los antiguos frente a las aspiraciones absolutistas del rey.

15 María del Carmen BARCIA et. al. (ed.), Historia de Cuba. La Colonia, evolución socioeconómica y formación nacional, de los orígenes hasta 1867, La Habana, 1994, pp. 319-327. 
Ese contexto explica la especificidad cubana en el período de las revoluciones y las particularidades que tuvo en la isla el régimen constitucional. Cuba es uno de los territorios que componía la monarquía en los que más tiempo estuvo vigente la Constitución, debido a que la isla no se vio envuelta en las guerras independentistas que asolaron a los territorios de la América continental. La Constitución de Cádiz fue proclamada por primera vez allí en julio de 1812 y estuvo vigente hasta finales de 1814. Fue reinstaurada entre 1820 y 1823 (Trienio Liberal en España) y otra vez, entre septiembre y diciembre de 1836, pero esta vez solamente en Santiago de Cuba y su jurisdicción.

La instauración del nuevo régimen suponía que por primera vez se elegirían ayuntamientos mediante elección popular, aunque esta estuviese restringida a los hombres de origen europeo o indígena americano, lo que en el Caribe significaba excluir a una parte significativa de la población masculina. Por primera vez se instaurarían también órganos de representación territorial (diputaciones provinciales) y se elegirían mediante sufragio popular diputados a las Cortes españolas. Además, la Constitución abría las puertas al surgimiento de nuevos ayuntamientos en las poblaciones a través del artículo 310 y conllevaba la división del territorio en partidos y provincias ${ }^{16}$. Aunque las atribuciones del capitán general de la isla no variaron significativamente, el establecimiento de órganos representativos para el gobierno del territorio supuso un cambio relevante en la vida política y la entrada a ella de sectores hasta entonces excluidos de las instituciones de gobierno tradicional. Pero los cambios que trajo el sistema constitucional no afectaron solamente al ordenamiento territorial de la isla y a la movilización política de sectores populares y de las clases medias a través de las elecciones. La creación de las milicias nacionales, el nombramiento de jueces de letras encargados de la justicia de primera instancia (tradicionalmente en manos de los alcaldes) y el ejercicio de la libertad de imprenta (decretada por las Cortes desde 1810) tuvieron gran trascendencia y fueron fuentes de conflictividad durante los períodos en que estuvo vigente la Constitución gaditana.

La llegada a Cuba del texto de la Constitución en 1812 fue precedida de las ritualidades que previeron las Cortes para su juramento y entrada en vigor. Los jefes políticos provinciales recibieron la orden de cómo debía llevarse a cabo el peculiar proceso diseñado por los diputados para dar inicio al nuevo régimen. Los clérigos tuvieron el papel de oficiantes y maestros de ceremonia, lo que auto-

16 «Se pondrá ayuntamiento en los pueblos que no le tengan, y en que convenga le haya, no pudiendo dejar de haberle en los que por sí o con su comarca lleguen a mil almas, y también se les señalará término correspondiente». 
máticamente les delegaba una responsabilidad a modo de funcionarios del nuevo Estado. No sólo habría repiques de campanas para dar noticias al pueblo de la llegada del código constitucional, sino que este debía ser jurado por «todas las autoridades civiles y eclesiásticas, los cuerpos de cualquier clase, [...], en todas las catedrales, Iglesias, universidades y comunidades religiosas». Antes del juramento los curas debían leer el texto y hacer «una breve exhortación correspondiente al objeto» y después del juramento debían celebrar una misa de acción de gracias y Te Deum. Durante los meses de julio y agosto de 1812 se llevaron a cabo los juramentos y fiestas de entronización del régimen constitucional por toda la isla, desde las capitales hasta los más remotos ayuntamientos rurales, sin que se tenga noticias de incumplimientos o disturbios.

\section{LA IGLESIA Y EL ALTO CLERO CUBANO ANTE EL NUEVO RÉGIMEN}

A inicios del siglo XIX la isla de Cuba se encontraba dividida en dos provincias eclesiásticas, con sede en La Habana y Santiago de Cuba, respectivamente. La diócesis habanera, que abarcaba la región centro occidental, fue constituida en 1789 y compartía sede con las máximas autoridades político-militares. La preeminencia económica, cultural y demográfica de la región en torno al puerto y ciudad de La Habana sobre el resto de la isla era indiscutible, lo que daba también preponderancia al obispo habanero frente al arzobispo de Santiago que, sin embargo, ostentaba la dignidad de metropolitano. El primer tercio del siglo estuvo marcado por los episcopados de Juan José Díaz de Espada y Fernández de Lan$\mathrm{da}^{17}$ (La Habana) y Joaquín de Osés y Alzúa ${ }^{18}$ (Santiago de Cuba), que ocuparon sus respectivas sillas durante todo el período que estudiamos.

Ambos prelados demostraron un talante ilustrado, especialmente en sus políticas de reforma diocesana, que incluyeron, entre otras cuestiones, propuestas para el fomento del territorio y de control y regulación de las órdenes religiosas y del clero secular, así como la erección de nuevas parroquias rurales y el saneamiento de sus cuentas. Si bien el pensamiento de Osés es menos conocido, el espíritu reformista y la adhesión a las corrientes regalistas está bien documentada en el caso de Espada. Precisamente por eso, el obispo gozó de gran popularidad y

17 Cfr. Fernández Mellén, Iglesia y poder en La Habana. Fuan fosé Díaz de Espada, un obispo ilustrado (1800-1832), Bilbao, 2015.

18 Cfr. Ana IrISARri Aguirre, El Oriente cubano durante el gobierno del obispo foaquín de Osés y Alzúa (1790-1823), Pamplona, 2003. 
del respeto de las élites y los gobernantes ${ }^{19}$, aunque el modelo de fomento económico que deseaban ambos para la isla no coincidiese con el de los plantadores ${ }^{20}$. Cuando se instaura el régimen liberal en España, la Iglesia cubana se encontraba en fase de expansión, estrechamente vinculada al crecimiento de la agricultura exportadora (y por consiguiente de la esclavitud) y al servicio del reforzamiento de las estructuras políticas y administrativas de la monarquía en la isla.

El alto clero cubano, encabezado por los dos obispos, aceptó y celebró la llegada del régimen constitucional. A Espada, particularmente, se le atribuye la promoción de un grupo de jóvenes habaneros formados en el más refinado reformismo ilustrado, defensores del régimen liberal. La mayoría de ellos se formaron en el colegio seminario de San Carlos, al que el obispo dio un impulso decisivo, y más en concreto en el curso de Constitución que, por mandato de las Cortes y encargo del propio Espada, impartió durante el curso 1820-1821 el presbítero Félix Varela ${ }^{21}$. Además de eso, ambos obispos fueron elegidos diputados a las Cortes nacionales en representación de sus respectivas provincias. Espada para el período 1814-1815 ${ }^{22}$ y Osés para el período 1820-182 $1^{23}$. Aunque ninguno de los dos llegó a ocupar su asiento en Cortes, la elección demuestra su buena sintonía con el régimen y con las élites de la isla. Espada no pudo asistir a las Cortes porque aquel mismo año el rey Fernando VII decretó su supresión. Osés alegó que su elección era inconstitucional de acuerdo con el artículo 97 del texto, que rezaba que «Ningún empleado público nombrado por el Gobierno podrá ser elegido

19 Sobre la formación de Espada y su particular trayectoria dentro del clero español, ver Andoni ARTOLA RENEDO, El acceso al episcopado en la monarquía hispánica (1789-1800), en Juan Bosco AMORES CARREDANO (dir.), Los tiempos de Espada: Vitoria y La Habana en la era de las revoluciones atlánticas, Bilbao, 2014, pp. 23-54. Para más información sobre la labor reformista del obispo y su marcado carácter regalista ver, además de la monografía ya citada de la misma autora, Consolación FERNÁNDEZ MELLÉN, En mejor servicio de Dios y del Rey: el obispo Espada y la reforma eclesiástica de Iglesia habanera, en ibid., pp. 141-162.

20 El modelo económico propugnado tanto por Espada como por Osés se acercaba más al ideal fisiocrático de una Cuba poblada por colonos europeos libres que al agroexportador y esclavista de la élite habanera. No obstante, a excepción de la disputa por los diezmos que se dio en los primeros años del siglo XIX, las reformas impulsadas por el obispo gozaron del apoyo de gobernantes y potentados. Cfr. María del Carmen BARCIA et. al. (ed.), Historia de Cuba ... [ver n. 15], pp. 327; y Ana IRISARRI AGUIRRE, El informe del obispo Joaquín de Osés y Alzúa: un intento ilustrado de promocionar el oriente cubano, en Temas americanistas, 16 (2003), pp. 81-95.

21 María del Carmen BARCIA et. al. (ed.), Historia de Cuba ... [ver n. 15], p. 327.

22 SEVILLA-ARCHIVO GENERAL DE INDIAS (AGI), Ultramar 115. Elecciones de diputados a Cortes, La Habana, 14-IV-1814.

23 AGI, Ultramar, 105, f. 737 bis. Carta de Eusebio Escudero al Secretario de Despacho de Ultramar, 11-VII-1820. 
Diputado de Cortes por la provincia en que ejerce su cargo». Tras manifestar la junta provincial de Santiago sus dudas a las Cortes, estas confirmaron que los episcopados eran cargos públicos, por lo que Osés fue sustituido por su suplente, Esteban Tamayo ${ }^{24}$. Los obispos no fueron los únicos clérigos elegidos diputados por las dos provincias en que fue dividida la isla. Juan Bernardo O'Gavan, provisor y vicario de La Habana, fue elegido diputado por Santiago de Cuba en 1810 para las Cortes Constituyentes y en 1820 por La Habana. El presbítero Félix Varela también elegido diputado por la provincia de La Habana para el período 1822-1823, y destacó por su defensa de un proyecto de gobierno autonómico para Cuba ${ }^{25}$.

La adhesión del alto clero al régimen constitucional se evidenció desde la proclamación de la Constitución y fue constante durante los dos períodos constitucionales. La postura de ambos prelados puede considerarse de prudente, atendiendo las dificultades del contexto regional e internacional en que se desempeñaban. La tranquilidad con que fue proclamada la Constitución en 1812 contrastó con las alteraciones de 1820. La llegada de las noticias del alzamiento de Riego y la jura de la Constitución por el rey provocaron serios disturbios en las dos ciudades más importantes de la isla. Contrastaron la efusividad popular de los cuerpos de militares destacados en la isla con el recelo manifiesto de las autoridades ${ }^{26}$. La reticencia inicial del capitán general Juan Manuel de Cagigal a proclamar la Constitución en 1820 se debió seguramente al desbordamiento de fuerzas que se produjo en La Habana, inusitado hasta entonces, y por el temor a que la noticia no fuera más que una falsa alarma que pudiese soliviantar la plaza. Esta reticencia le valió la crítica demoledora del sector más exaltado de la ciudad, representado por los comerciantes peninsulares de la calle Muralla, que le desacreditaron a través de la prensa mientras duró su corto mandato.

La polémica también salpicó al obispo Espada, quien fue acusado de estar contra la Constitución por la demora que tuvo en celebrar la vuelta del orden liberal, a diferencia de la actitud que había mantenido en 1812. El obispo se vio obligado a dar explicaciones mediante una carta pastoral. En ella no solo se

24 Colección de decretos y órdenes generales de la primera legislatura de las Cortes ordinarias de 1820 y 1821 , desde el 6 de julio de 1820 basta el 9 de noviembre de 1820. T-VII, p. 30.

25 Sobre los diputados cubanos a las Cortes liberales, ver Elías ENTRALgo, Los diputados por Cuba en las Cortes de España durante los tres primeros períodos constitucionales, La Habana, 1944. Sobre Varela: José Antonio PIQUeras ARENAS, Félix Varela y la prosperidad de la patria criolla, Madrid, 2007.

26 Leví Marrero, Cuba: Economía y Sociedad. Azúcar, Ilustración y Conciencia (1763-1868), t. 15, Madrid, 1992, pp. 44-47. 
sumaba al júbilo general y bendice la Carta Magna, sino que da instrucciones a los curas de la diócesis para que expliquen al pueblo los domingos el «doble catecismo religioso-político», con esta exhortación: «hacedles entender que en este código están comprendidos radicalmente todos sus más esenciales derechos y obligaciones como ciudadanos» ${ }^{27}$. Muy pronto tuvo oportunidad de demostrar que su ideario reformista ilustrado le acercaba al régimen liberal, a pesar de la prudencia que mantuvo en los primeros días de su proclamación. Espada dio todo su apoyo al intendente Alejandro Ramírez en la aplicación de la ley de monacales aprobada por las Cortes el 25 de octubre de 1820. Como resultado inmediato, el año siguiente fueron suprimidos nueve conventos en la isla y los obispos incrementaron su control sobre los persistentes ${ }^{28}$.

En 1822 el propio Espada ofició en la catedral habanera el acto de ampliación de la tumba de Cristóbal Colón, acompañado de su cabildo catedralicio, del jefe superior político de La Habana y de varios miembros de la diputación provincial y el ayuntamiento de la capital. Junto al nicho de Colón, mandó colocar una edición grande de la Constitución, además de la «gran medalla de oro acuñada en Cádiz» más un busto de Fernando VII y medallas de otros reyes antecedentes $^{29}$. Sin duda, la erección de este altar patrio y la divulgación en la prensa de los detalles del acto en momentos de gran tensión política en la península, fue una maniobra política para demostrar las simpatías del prelado y de las instituciones habaneras al régimen liberal.

\section{El CLERO SECULAR CUBANO Y LA INSTAURACIÓN DEL RÉGIMEN REPRESENTATIVO}

El resto de la clerecía también se involucró en la instauración del nuevo orden político. Uno de los pilares, y a la vez novedades que introducía el nuevo régimen español era su carácter representativo. La organización política se estructuró, desde la base hasta la cúspide, en ayuntamientos, diputaciones y Cortes generales. El sistema electivo también se reguló en el articulado de la Constitu-

27 AGI, Ultramar, 375, Circular de Espada A los cura párrocos, sacristanes mayores, y tenientes perpetuos de las iglesias de su obispado, a los superiores regulares y demás individuos encargados de la enseñanza pública, principalmente a los catedráticos de jurisprudencia, a consecuencia de la real orden de cuatro de mayo de mil ochocientos veinte sobre la aplicación de la Constitución política de la monarquía española, 1820.

28 Edelberto Leiva Lajara, La orden dominica en La Habana. Convento y sociedad (1578-1842), La Habana, 2007, pp. 237-244.

29 AGI, Periódicos, 5/41, Gaceta de La Habana, nº 64, 27/10/1822. 
ción y se perfiló, posteriormente, mediante el decreto de las mismas Cortes de 23 de mayo de 1812, estableciéndose un sistema indirecto en tres grados: parroquias, partidos y provincias ${ }^{30}$. Unas juntas electorales de parroquia surgidas del voto de todos los vecinos escogían a los electores de partido, que a su vez votaban a los electores de provincia; estos, reunidos en la cabecera de la provincia, elegían a los diputados a Cortes y al día siguiente a los miembros elegibles de la diputación provincial. A continuación, la nueva diputación provincial debía decidir sobre las poblaciones en las que convenía establecer ayuntamiento y se celebrarían las elecciones correspondientes de forma similar a las anteriores: las juntas parroquiales votaban a los compromisarios, que designaban a los electores, que a su vez elegían a los alcaldes y regidores ${ }^{31}$.

La elección de la parroquia como circunscripción electoral base no sólo remitía a una institución primordial del antiguo régimen, sino que, como se ha analizado antes, era el elemento esencial en el que descansaba la nación católica diseñada por las Cortes. A la vez, y no menos significativo, los arquitectos del nuevo régimen asumían que no había una forma más fiable de identificar adecuadamente y reunir al censo. Sobre los párrocos descansaba la responsabilidad de proveer los censos de sus respectivas parroquias, pero también la de asistir a las juntas parroquiales, como autoridades locales que eran. Esto dio a los curas un papel central en la erección del régimen constitucional y una vía de influencia en los asuntos políticos locales.

En la realidad americana, y particularmente en la cubana, la verificación de los dos criterios (origen y religión) de los que dependían el disfrute de la condición de ciudadano se tornaba particularmente compleja, teniendo en cuenta el mestizaje de la población tras tres siglos de presencia de originarios de África entre la población libre de la isla y el sincretismo de sus expresiones culturales y religiosas. Como destaca Marcos Arriaga, ya en la segunda mitad del siglo XVI habanero, si bien no puede hablarse de igualdad entre blancos europeos y sus descendientes criollos por un lado y los «libres de color» por otro, muchos de estos últimos eran considerados como vecinos de la ciudad, aunque algunos de los derechos inherentes a esa condición les fueran coartados por ordenanzas del cabildo o por disposiciones del Consejo de Indias ${ }^{32}$. La formación de censos fia-

30 Colección de decretos y órdenes que han expedido las Cortes Generales y extraordinarias desde 24 de setiembre de 1811 hasta el 24 de mayo de 1812, t. II, pp. 210-220.

31 Enrique ORDUÑa REBOLLO, Municipios y provincias: historia de la organización territorial española, Madrid, 2003, pp. 287-310 y 320-329.

32 Marcos Arriaga Mesa, La Habana 1550-1600, Madrid, 2014, pp. 218-230. 
bles se convirtió en un reclamo constante del gobierno español a las autoridades habaneras y de estas a las autoridades locales de toda la isla.

Llama la atención, sin embargo, que a pesar del complejo panorama demográfico que presentaba la isla con vistas a organizar los censos electorales, apenas hay evidencias de disputas en las juntas por la comprobación de los dos criterios ${ }^{33}$. Esto puede deberse a que las juntas parroquiales en las que se dirimían estas cuestiones no dejaron actas que podamos revisar o, más probablemente, a que el acuerdo tácito entre las comunidades de parroquianos hizo menos relevante de lo que consideran los autores antes mencionados el cumplimiento estricto de las condiciones de limpieza de sangre y catolicidad. Sucedió lo mismo con las insinuaciones que aparecían en la prensa exaltada sobre el probable origen africano de ciertos enemigos políticos. Existen algunas, provenientes fundamentalmente de los círculos de inmigrantes peninsulares contra los criollos, pero no ocuparon un papel relevante entre los descalificativos que circularon en periódicos y panfletos políticos ${ }^{34}$.

La Constitución, en el capítulo III, dedicado a las juntas parroquiales, determinaba que estas se compondrían de todos los ciudadanos avecindados y residentes en la parroquia respectiva, incluyendo a los eclesiásticos seculares (art. 35); que debían ser presididas por el jefe político o alcalde, «con asistencia del cura párroco para mayor solemnidad del acto» (art. 46); y que tenían la capacidad de resolver en el acto, y sin que cupiese apelación, cualquier duda que se presentase sobre si los presentes en ella reunían todas las «calidades requeridas» para poder votar (art. 50). Además, sus actos deberían ser precedidos y finalizados en el templo, mediante la celebración de una Misa y Te Deum, en las que los párrocos deberían hacer «un discurso correspondiente a las circunstancias» (arts. 47 y 58). A los curas se reservaba no solamente la ritualidad que debía envolver la elección y las palabras de exhortación al régimen, sino también una participación activa en la junta. La falta de precisión respecto al contenido de esos discursos y los límites

33 En 1820 el cura Domingo Ambrosio de Aguirre (de origen alavés y vecino del partido rural de Cayajabos) representó a las Cortes con motivos de las elecciones celebradas en la provincia habanera para la elección de diputados nacionales. Según su testimonio, en algunas poblaciones se había actuado con total arbitrariedad en las juntas electorales, como en la Puerta de la Güira, donde habían contado a todos los vecinos, vulnerando el artículo 29 de la Constitución, que no reconocía el derecho de ciudadanía a los originarios de África por cualquier línea. Diario de las actas y discusiones de las Cortes: Legislatura de los años 1820 y 1821, Madrid, D. García y Campoy, 1820-21, T-12, p. 5 (disponible en http://catalog.hathitrust.org/).

34 AGI, Periódicos, 5/23, La corbeta constitucional, $\mathrm{n}^{\circ}$ 2, 5-VII-1822. En un escrito contra el padre Sánchez Lima y sus «secuaces», insinuaban que no eran «blancos españoles por ambas líneas» ni hijos legítimos hasta el quinto grado. 
del desempeño de los párrocos en esas sesiones electorales suscitaron varios conflictos durante los períodos electorales.

Los sucesos de mayor gravedad se registraron en las elecciones parroquiales de la villa de Bayamo, en diciembre de 1812. El cura párroco de la parroquia de San Juan Evangelista, Francisco Javier de Bobadilla, se enfrentó a un grupo de la élite local encabezado por Miguel Fornaris, por considerar que intentaban manipular las elecciones en su favor. Según su propio testimonio, tuvo que intervenir ante la inacción del presidente de la junta para impedir que vecinos de la parroquial mayor sufragaran allí y para que las «disputas turbulentas» y «una grotesca algazara» no acabaran con el acto. Bobadilla justifica su intervención, además, por la súplica que le hicieron a él sus feligreses «para que representara sus derechos ante tanto abuso y despotismo», lo cual le valió todo tipo de insultos y amenazas $^{35}$. Por lo que se deduce del expediente promovido por el jefe político superior de Santiago de Cuba, un año más tarde la situación seguía sin resolverse en Bayamo. En la junta electoral de parroquia de diciembre de 1813, se suscitaron varias dudas que fueron consultadas a la diputación provincial. La primera de ellas era si el cura párroco «que concurre a dicha junta para mayor solemnidad del acto se halla autorizado para impedir que sufraguen en ella individuos de distinta feligresía». Consultaban, además, si los habitantes de otro pueblo, transeúntes, de la misma o diferente provincia, podían votar hallándose en el que se celebrara la junta, y si los feligreses de una parroquia podían votar en otra ${ }^{36}$.

En 1823 varios electores parroquiales presentaron una queja contra la junta electoral que tuvo lugar en la hacienda de Iguará, correspondiente a la Iglesia auxiliar de Arroyo Blanco, una de las parroquias rurales en que se dividió la jurisdicción de Sancti Spíritus, en el centro de la isla. La queja buscaba impugnar los resultados de las elecciones, entre otros motivos, porque los miembros de la junta no habían dejado participar en ella al cura Basilio Madrigal. Según el testimonio, los miembros de la mesa (presidente, secretario y escrutadores) se reservaron las decisiones sobre la calidad de los votantes, excluyendo al cura porque, «interesados en la elección, excluían a los que eran contrarios», incumpliendo el artículo 50 de la Constitución. Este fue solo uno de los motivos para solicitar la repetición de las elecciones y los promotores de la denuncia demostraron su oposición al ayuntamiento electo ${ }^{37}$.

35 AGI, Cuba, 1840. Expediente de la diputación provincial de Cuba sobre el conflicto entre el teniente de gobernador de Bayamo y el alcalde primero José de Jesús Fornaris.

36 AGI, Santo Domingo, 1288. Pedro Suárez de Urbina a José Limonta, 14-IV-1814.

37 ARCHIVO HISTÓRICO PROVINCIAL DE SANCTI SPÍRITUS (AHPSS), Actas del cabildo de Sancti Spíritus, 9-II-1823. 
Los procesos electorales, por ser los primeros de esa naturaleza que se celebraban, y por ser el espacio idóneo para que se confrontaran las aspiraciones de distintos sectores de las élites locales, estuvieron plagados de irregularidades. El surgimiento de facciones políticas, que pugnaron por la representación territorial a todos los niveles, es uno de los elementos más significativos que reflejan las fuentes. La participación de los clérigos en la instauración del nuevo régimen político en Cuba, cuyo epicentro fueron precisamente las elecciones, no puede analizarse fuera del contexto de esas luchas políticas, que si bien existirían desde antes, encontraron nuevas vías para ser canalizadas.

Además de la autoridad que la Constitución les reservó como oficiantes de la liturgia constitucional y guardianes del censo, los clérigos seculares también obtuvieron el derecho a participar activamente en las elecciones, como miembros de las juntas electorales de parroquia, como electores parroquiales y de partido, como miembros de las diputaciones provinciales y como diputados a las Cortes generales, si resultaban electos en sus respectivas circunscripciones (tanto las de origen como aquellas en que estuviesen avecindados). En todo eran asimilados al conjunto de los ciudadanos, excepto en que como empleados públicos de nombramiento real no podían ser elegidos para representar a la circunscripción en la que se desempeñaban ${ }^{38}$.

La presencia de los curas en las juntas electorales de parroquia garantizaba la validez del censo y también el control de los resultados a través del ejercicio de su autoridad. La nominación de compromisarios por parte de la ciudadanía no era secreta, sino que se hacía a viva voz frente a la junta, de la cual formaban parte el cura y el jefe político, si lo había, además de alcaldes y regidores. El método garantizaba una mayor influencia de los notables, entre ellos el cura, ya que normalmente eran los primeros en dar su voto frente a los demás convocados, de la misma manera que se hacía posteriormente en las juntas de electores. Más adelante, durante el Trienio, se cambió el sistema y las elecciones pasaron a ser secretas. Tras estas juntas, se celebraban, con parecido ceremonial, las de electores. En este caso la presencia del cura, aparte de la celebración de la misa, solo estaba garantizada si resultaba previamente nominado, lo cual dio lugar a algunas

38 Constitución política de la Monarquía Española, artículo 318: «No podrá ser alcalde, regidor ni procurador síndico ningún empleado público de nombramiento del Rey, que esté en ejercicio, no entendiéndose comprendidos en esta regla los que sirvan en las milicias nacionales». Interpretación ratificada y ampliada al caso de los diputados, en el caso de la elección del obispo Osés como diputado a Cortes. Colección de decretos y órdenes generales de la primera legislatura de las Cortes ordinarias de 1820 y 1821, desde el 6 de julio de 1820 basta el 9 de noviembre de 1820, t. VII, p. 30. 
tensiones. Si bien no son numerosos, varias fuentes consultadas corroboran que la ambigüedad de los artículos de la Constitución sobre los límites de la labor de los curas dio lugar a varias disputas y confusiones, que se localizaron mayormente en los nuevos ayuntamientos constitucionales creados en los años 1813 y $1814^{39}$.

Solo ha sido posible para este trabajo la reconstrucción casi completa de los procesos electorales llevados a cabo durante los dos períodos constitucionales en las jurisdicciones de Sancti Spíritus y Puerto Príncipe, tanto de las cabeceras urbanas como de las parroquias rurales. En ambos casos se aprecia una participación muy activa de los clérigos y su presencia casi permanente en las juntas de electores. No puede decirse, sin embargo, que constituyeran elementos hegemónicos de los procesos, como lo observado en otros territorios americanos ${ }^{40}$. Los primeros ayuntamientos constitucionales se instalaron en Cuba en el verano de 1812 en las villas y ciudades que ya contaban con cabildos provenientes del antiguo sistema, en las que se sustituyeron las regidurías perpetuas por las electivas. En la mayoría de casos, la disputa por ocupar los cargos de los nuevos ayuntamientos se produjo entre sectores de las élites locales, que se habían reproducido en la tradición institucional previa. La poca entidad de flujos migratorios hacia la mayor parte del interior del territorio cubano, exceptuando a La Habana y sus alrededores, garantizó que en el nuevo régimen se dirimieran viejas rencillas entre clanes familiares que ya venían disfrutando del poder local. Los curas, criollos o acriollados, se insertaban en los mismos grupos de intereses y, como tal, aprovecharon su doble condición de ciudadanos y delegados del Estado para influir en los resultados.

En las primeras elecciones para empleos concejiles que se llevaron a cabo en Puerto Príncipe se evidenció, a través de una conflictividad inusitada por el control de los resultados, la división de la élite local. El teniente de gobernador de la villa, Francisco Sedano, cuya autoridad como jefe político subalterno fue seriamente cuestionada por el sector dominante de la élite local, informó al capitán de los disturbios, denunciando que una facción encabezada por el coronel

39 En las elecciones parroquiales de Pinar del Río, celebradas el 15 de agosto de 1813, los miembros de la junta de electores no permitieron al cura intervenir en la misma, por no haber sido elegido como tal, lo cual hicieron reflejar en el acta. AGI, Ultramar, 115. Juan Ruiz de Apodaca a José Limonta, sobre instalación de los ayuntamientos constitucionales en Cuba, 17-XI-1813.

40 Marco BeLlingeri, Las ambigüedades del voto en Yucatán. Representación y gobierno en una formación interétnica, 1812-1829, en Antonio ANNINO (coord.), Historia de las elecciones en Iberoamérica, siglo XIX. De la formación del espacio político nacional, 1995, pp. 248-256. Bellingeri denomina a los curas «seductores de indios» por la gran influencia que ejercieron sobre estos durante los procesos electorales. 
del batallón de milicias Ignacio Antonio de Varona, el oficial de marina Diego Antonio del Castillo y los presbíteros Diego Alonso y Juan de Dios Betancourt «trabajaban con ideas de seducir a los incautos del pueblo y forzar la tropa para obtener en el nombramiento de electores que formaran luego a su arbitrio el ayuntamiento de sus partidarios y parientes (...) siendo todo el cabildo de parientes y confabulados» ${ }^{41}$. El resultado de las elecciones no dejó lugar a dudas sobre el triunfo rotundo de esa facción de la élite criolla tradicional. Todos los puestos del ayuntamiento fueron copados por una estrecha red de parentescos de primer grado, nucleada en torno al alcalde y al coronel $^{42}$. Los apellidos Castillo, Varona, Agüero, y Betancourt, estrechamente vinculados entre sí por lazos familiares, y reproducidos en los cuerpos de milicias locales, demostraron ser un grupo muy cohesionado, capaz de controlar el poder local. La única excepción fue el puesto de segundo alcalde para el que, precisamente gracias al nuevo sistema electoral representativo, resultó elegido Santiago Hernández, enemigo político del primero y representante de un grupo de peninsulares ${ }^{43}$.

Tanto Castellanos como Sedano insistieron en la estrecha colaboración de algunos eclesiásticos en el «complot», especialmente Diego Alonso Betancourt, Juan de Dios de Betancourt y Miguel González, quienes habrían trabajado abiertamente «seduciendo a incautos» y «congraciándose con los caudillos». Otra vez aparecen las implicaciones directas con el grupo que promovió el intento juntista de 1809 , defendido por un amplio sector del clero. En aquella ocasión, el único procesado fue el presbítero Domingo Espinosa, pero tras él fueron señalados como principales inductores el vicario foráneo de la villa y el cura de la Iglesia auxiliar de la Caridad, Francisco de la Torre y el mismo Diego Alonso de Betancourt ${ }^{44}$. Este último, primo hermano del primer alcalde y hermano de dos regidores, fue elegido elector parroquial. No parece casual, sino resultado de complicidades con el grupo que controlaba el poder local, la fuga del presbítero Espinosa, que había sido encausado por la Audiencia y recluido en el convento de San Francisco de aquella villa ${ }^{45}$, a pesar de que

41 AGI, Cuba, 1820. Oficio de Francisco Sedano a Juan Ruiz de Apodaca, 26-IX-1812.

42 AGI, Cuba, 1820. 25-IX-1812. Memorial de Rafael Castellanos a las Cortes. Castellanos era escribano de gobierno de la villa y con el acceso al poder del grupo de Castillo, perdió el puesto de secretario del nuevo ayuntamiento.

43 AGI, Cuba, 1820. Copia del acta del cabildo de Puerto Príncipe del 24-XI-1812.

44 Sobre el intento juntista en Puerto Príncipe, ver Consolación FERnández MELlÉn, A la zaga de La Habana: El intento autonomista de Puerto Príncipe de 1809, en Josef OPaTrNÝ (ed.), Pensamiento caribeño: siglos XIX y XX, Praga, 2007, pp. 145-156.

45 AGI, Cuba, 1820. Sedano a Apodaca, 12-XII-1812. 
no se hace mención explícita de esta conexión en las fuentes consultadas. En la junta de electores celebrada un año más tarde, en diciembre de 1813, para la renovación del ayuntamiento constitucional, del total de veinticinco electores parroquiales que la componían, seis eran clérigos: Tomás de Borrero, Álvaro Montes de Oca, Agustín Porro, Miguel Gómez, José María González y Victoriano de Varona ${ }^{46}$.

En Puerto Príncipe, durante el primer bienio constitucional la presencia de los curas es constante en las juntas, pero no se aprecia claramente un liderazgo de estos dentro de las facciones políticas en pugna, sino más bien el aprovechamiento de su posición para servir a las redes familiares en que se insertaban. Sin embargo, en Sancti Spíritus, otra de las villas antiguas de la isla, con gran tradición institucional, se aprecia claramente durante el Trienio el surgimiento de un liderazgo claro por parte del cura rector de la parroquial mayor, Félix Madrigal, que fue nombrado elector parroquial en todas las juntas que se llevaron a cabo en aquellos años. Nombrado «primer elector», era él el primero en nombrar a sus candidatos para ocupar las alcaldías, regidurías y sindicaturas del ayuntamiento. En todos los procesos se advierte perfectamente que existían acuerdos previos y afinidades de partido o facción, que agrupaban los votos. En 1820, cuando sólo existía una junta parroquial en la jurisdicción, la hegemonía de Madrigal en ella fue absoluta, frente a las propuestas de otro miembro de la élite local, el coronel de infantería de milicias disciplinadas de los cuatro pueblos ${ }^{47}$ y jefe militar de la plaza de Sancti Spíritus, Fernando Alfonso del Valle ${ }^{48}$. En las elecciones de agosto de 1821 para el nombramiento de un tercer alcalde (cumpliendo con las disposiciones de las Cortes), se repitió el enfrentamiento entre Valle y Madrigal, consiguiendo este segundo que todos los electores votaran su propuesta. Teniendo en cuenta que Valle provenía de la parroquia auxiliar, se puede inferir que Madrigal respondía a los intereses del grupo de la parroquial mayor (el de la élite) al que también pertenecían Tomás de Pina y Nicolás Estrada, a los que propuso para ocupar las alcaldías y fueron protagonistas de algunos de los sucesos más destacados de la política local durante el Trienio.

46 ARChivo histórico Provincial De CAMagüEY (=AHPC), Actas del cabildo de Puerto Príncipe, 26-XII-1813.

47 Cuatro pueblos, cuatro lugares o cuatro villas fueron las denominaciones que tuvo la tenencia de gobernación central de la isla, con capital en la ciudad de Trinidad y que integraba también a las villas de Sancti Spíritus, Santa Clara y Remedios.

48 AHPSS, Actas del cabildo de Sancti Spíritus, 3-XII-1820. 
Los electores de la villa, aunque divididos entre las parroquias de la Caridad y la Mayor, coincidían en defender la concurrencia a Sancti Spíritus de todos los ciudadanos de la jurisdicción, frente a los intereses rurales, organizados en torno a las parroquias auxiliares erigidas por impulso del obispo Espada. El sacerdote Antonio José López, cura de Morón, asumió la defensa de los intereses de la población rural frente a la urbana y se convirtió así en otro de los personajes más destacados del período. Fue elegido elector parroquial en 1813 y en la junta abanderó una propuesta de los partidos rurales para colocar en el ayuntamiento a sus afines, frente a la del entonces alcalde de segunda elección, Gregorio Pentón, que también ejercía como elector. La votación fue muy ajustada, dividida entre el partido rural y el urbano. Ganaron los últimos, porque las parroquias urbanas tenían un número más elevado de electores ${ }^{49}$. El cura López, al frente de los electores de Arroyo Blanco, el Jíbaro, San Eugenio de la Palma y Morón, intentó ganar el ayuntamiento, lo que habría representado una auténtica revolución local, después de que, infructuosamente, hubiesen solicitado al cabildo la formación de juntas parroquiales en sus respectivos vecindarios, separadas de las de la villa ${ }^{50}$. Con ello buscaban aumentar su representación, pues la extensión territorial de la jurisdicción hacía muy difícil que los pobladores de las partes más alejadas acudieran a la villa los días señalados para las elecciones, pero también aumentar su capacidad de influencia en dichas juntas. La derrota electoral no calmó los ánimos y apenas una semana después de proclamados los resultados el cura encabezó una protesta al nuevo ayuntamiento, junto a otros siete electores, pidiendo copias de las actas de la junta para elevar queja a la diputación provincial ${ }^{51}$. No solo querían junta propia, sino que reclamaban la repartición igualitaria del número de electores entre todas las parroquias que componían la jurisdicción, con un modelo de representación territorial y no de habitantes, pues la desproporción entre las dos parroquias urbanas y las cuatro rurales seguía siendo considerable a favor de las primeras.

La jurisdicción espirituana abarcaba un espacio mayor al que actualmente ocupa la provincia cubana del mismo nombre, y el crecimiento demográfico de las últimas décadas, si bien no tenía la misma entidad que el que se había producido en el entorno de La Habana, había creado núcleos de población dispersos pero de un tamaño considerable. Las reformas de Espada habían dotado a estos núcleos de parroquias auxiliares, contribuyendo así a la reorganización de ese

49 AHPSS, Actas del cabildo de Sancti Spiritus, 28-XII-1813.

50 Ibid., 3-XII-1813.

51 Ibid., 7-I-1814. 
hábitat disperso en torno a pequeñas poblaciones que, una vez instaurado el régimen representativo, vieron la oportunidad de ganar en autonomía. La lectura de las actas de las juntas y de las peticiones insistentes del ayuntamiento y de los jefes políticos para que se elaboraran censos de la región demuestra que la entidad de ese crecimiento continuaba siendo desconocida por las autoridades y por las poblaciones mismas. La necesidad de poner en pie el sistema electoral con la división del territorio en parroquias también evidenció que ni siquiera se conocían bien los límites de las mismas y la importancia de sus núcleos, pues en muy poco tiempo (después de la erección de las auxiliares por Espada) las poblaciones se habían reasentado en dependencia de los intereses económicos o de las condiciones del espacio. Este desconocimiento hacía de los curas figuras centrales en la defensa de los intereses de estos territorios y en partidarios de una mayor autonomía para ellos, a través de la constitución de juntas electorales propias o, si los censos lo permitían, de ayuntamientos separados de sus matrices, como fue el caso de Morón, que consiguió un ayuntamiento propio a finales del Trienio ${ }^{52}$.

Un protagonismo similar al del cura Antonio José López en la jurisdicción de Sancti Spíritus lo tuvo el presbítero Antonio José Galán en el dilatado proceso de creación de un ayuntamiento para las poblaciones de San Diego, Cacaragícara (partido de Filipinas) y Bahíahonda (partido de Guanajay), en la parte más occidental de la isla. La diputación habanera había concedido la creación de dicho ayuntamiento en 1821, pero las tres poblaciones se disputaban el papel de cabeceras locales para acogerlo. El envío de una comisión por parte de la diputación para comprobar los padrones puso en alerta a los vecinos. Antonio Galán, cura de los tres lugares en la parroquia de Cacaragícara, pero residente en San Diego, dirigió junto a otros vecinos del pueblo una representación al capitán general en abril de 1821 fundamentando la idoneidad de San Diego para acoger la casa consistorial ${ }^{53}$. La resolución se prolongó más de un año, pues el 30 de marzo de 1822 fueron un grupo de vecinos de Bahíahonda y Cacaragícara los que alerta-

52 En 1820, al poco tiempo de reinstalado el ayuntamiento constitucional de Sancti Spíritus, el cura López dirigió una representación a la diputación habanera solicitando la erección de un ayuntamiento propio en el partido de Morón, en virtud de contar con el número de almas que estipulaba la Constitución para ello, de acuerdo al último censo de 1817. AHPSS, Actas del cabildo de Sancti Spíritus, 7-VII-1820. En 1823 fueron los vecinos de Ciego de Ávila, otra hacienda de la jurisdicción, más distante de la villa que Morón, los que pidieron ayuntamiento propio, AHPSS, Actas del cabildo de Sancti Spíritus, 17-II-1823.

53 MADRID-ARCHIVO HISTÓRICO NACIONAL (AHN), Estado, 2, 62. Expediente sobre la creación de un ayuntamiento para San Diego, Bahíahonda y Cacaragícara. 
ron al capitán general sobre los manejos del cura Galán para conseguir que San Diego fuese la cabecera del nuevo ayuntamiento, para favorecer sus intereses particulares

... al dicho cura le mueve para hacer esta solicitud el estar fomentando un cafetal casi lindando con San Diego, el interés que tiene en un almacén de víveres situado en el mismo, y el juzgar que la estancia de esta municipalidad allí daría importancia y valor a sus bienes rústicos y urbanos consistentes en lo dicho, y en la casa de su morada. No es de extrañar que el cura tuviese inclinación al pueblo de San Diego (...) pero lo que no es de admirar que confundiendo sus miras particulares con las del bien público, pretenda oscurecer estas por obtener aquellas ${ }^{54}$.

Acusaron al cura de manipular el censo, incluyendo a casas que estaban muy distantes del pueblo e incluso a bohíos de negros. Además, dijeron que mientras que en Bahíahonda los vecinos costearon una ermita y pagaron un capellán, Galán estuvo veintiún años «celebrando misa en el colgadizo de la casa que habita con familia» hasta que el año anterior había levantado una Iglesia con horcones. A todo ello sumaron las ventajas naturales de Bahíahonda, situada en la bahía, en un terreno llano y con posibilidad de crecer, por cuyo embarcadero se realizaba todo el comercio del partido ${ }^{55}$.

\section{LA OPINIÓN PÚBLICA Y LA CRÍTICA AL CLERO CUBANO}

El involucramiento de los curas en la creación de nuevos ayuntamientos constitucionales debió ser muy notable, pues a finales del año 1821 el periódico habanero de tendencia exaltada, El esquife arranchador, le dedicó una de sus populares secciones satíricas. En ella, el jefe político imaginario de la isla, el doctor Chilibrán, dictaba un bando sobre los «villorrios, pueblecillos y aldehuelas de la isla que han solicitado y solicitan formar sus ayuntamientos constitucionales», mandando que fueran conducidos a su presencia por serviles e inconstitucionales «todos los curas intrigantes que abusando del piadoso y justo respeto que los pueblos les profesan, hagan valer su preponderancia, obstruyan y malogren directa o indirectamente la libertad de las elecciones, pues estas deben ser espontáneas y de ningún modo parecidas a las que se ejecutaron en San Jerónimo del Peñalver

54 Ibidem.

55 Están sugiriendo también la idea de que vive amancebado. Los descalificativos personales y las ofensas acapararon la mayor parte de los enfrentamientos a través de la prensa. 
el año de 1814, cuyo alcalde concedió al padre cura el honroso título de director de la junta parroquial, título que no se haya en la Constitución» ${ }^{56}$.

Fue en La Habana donde la intervención de los curas en la vida política constitucional tuvo un espacio más relevante en los debates públicos. $\mathrm{El}$ ambiente de la ciudad estuvo mucho más caldeado que en las villas y lugares del interior, especialmente por la notable influencia que tuvo allí la libertad de imprenta decretada por las Cortes en 1810. La profusión de publicaciones periódicas durante los dos períodos constitucionales llevó una parte considerable del debate público a las páginas de diarios, semanarios y folletos que se imprimían en la ciudad. El puerto de La Habana y la expansión económica que venía experimentando la región habanera desde finales del siglo XVIII convertían a la ciudad en el espacio más complejo de la isla. Entre ellos, cabe destacar la importante presencia de militares de paso entre la península y las guerras del continente, españoles y criollos americanos que se habían establecido temporalmente en la ciudad buscando el abrigo que ya no ofrecían otros puertos como Buenos Aires, Cartagena de Indias o Caracas, sumados al nutrido grupo de criollos blancos, libres de color y esclavos. En ese contexto, las pugnas por ocupar el poder político mostraron un nivel de conflictividad mayor que el analizado hasta ahora e involucraron a otros sectores sociales, además de las élites tradicionales.

Una de las figuras centrales del debate político en la ciudad durante los períodos constitucionales fue el clérigo español Tomás Gutiérrez de Piñeres, que había llegado a La Habana como servidor del primer obispo de la diócesis, Domingo de Trespalacios, y que estaba muy vinculado a los grupos de comerciantes peninsulares que se asentaban en la calle Muralla ${ }^{57}$. La labor política de Piñeres, y especialmente su papel de panfletista o libelo, es mucho más conocida por la historiografía que la de otros clérigos que también participaron activamente en la vida pública de aquellos años. Piñeres lideraba la facción colonialista de los comerciantes peninsulares que pretendía reducir el poder de las elites tradicionales aliadas del capitán general y, en los años en que estuvo vigente, aprovechó la libertad de prensa para agitar intensamente la opinión pública habanera, presentándose como defensor de las libertades constitucionales frente a aquellos, aunque él mismo no era precisamente un liberal.

56 AGI, Periódicos 5/24, El esquife arranchador, n. 26, 1-XI-1820.

57 Cfr. Juan B. AMORES CARREDANO, Liberalismo ilustrado y liberalismo político en Cuba: en torno a Francisco de Arango y Parreño (1764-1837), en Manuel CHUST e Ivana FRASQUET (eds.), Los colores de las independencias iberoamericanas: Liberalismo, etnia y raza, pp. 49-88, Madrid, 2009, pp. 71-73. Sobre Piñeres y el obispo Trespalacios, ver Consolación FERNÁNDEZ MELLÉN, Iglesia y poder..., op. cit., p. 8ss. 
Durante el Trienio se hizo más encarnizada la pugna por controlar las elecciones y, a través de ellas, las instituciones representativas. La movilización de sus adeptos y el efecto de las proclamas incendiaras que dirigía Piñeres contra el jefe político superior y algunos miembros de la aristocracia habanera sirvieron para que la facción piñerista consiguiera inclinar a su favor el ayuntamiento constitucional de 1821 e influir en las elecciones a diputados a Cortes. En ambos procesos hubo notables irregularidades que provocaron la repetición de las elecciones parroquiales en barrios populosos de la ciudad y la anulación de las elecciones provinciales para el nombramiento de diputados, decretada por las Cortes el 23 de febrero de $1821^{58}$. La repetición de las elecciones se solapó con las convocatorias ordinarias para renovar el ayuntamiento, de tal forma que el período que va desde finales de 1820 hasta mediados de 1822 fue de movilización casi constante de la ciudadanía. A la vez, coincidió con un período especialmente álgido en la península, con la supresión de la Inquisición, la eliminación de los monacales y las conspiraciones antiliberales.

En ese contexto aparecieron en La Habana los primeros textos criticando a los clérigos por inmiscuirse en la política local. Las críticas provenían de la prensa contraria a Piñeres, y señalaban directamente al cura como manipulador de las elecciones para diputados a Cortes y creador de un partido o facción que alteraba el orden de la ciudad. En El falucho vigía se burlaban en nombre del pueblo habanero de los infructuosos esfuerzos de Piñeres por controlar los resultados, a través de la conversación entre dos vecinos imaginarios. El intercambio de acusaciones y descalificaciones entre adversarios políticos caracterizó a la prensa habanera del período, pero en pocas ocasiones rebasó esos niveles para adentrarse en debates doctrinarios o de corte más ideológico, como en la península. La mayor parte de las acusaciones contra Gutiérrez de Piñeres iban dirigidas contra su persona y sus manejos políticos:

Jacinto: (...) pero aseguran que dice el padre que él no se mete en nada de elecciones.

Blas: Qué tú eres bobo, Jacinto, el padre tira la piedra y esconde la mano, como si acá no se supiera esa gramática parda.

Jacinto: Como si el padre no se metiera en nada como pretende persuadir no fueran alcaldes sus mayores amigos, no fueran regidores sus adoradores, ni jurados los que le visitan casi diariamente ${ }^{59}$.

58 Diario de las actas y discusiones de las Cortes: Legislatura de los años de 1820 y 1821, Madrid, 1820-21, T. 12, p. 5).

59 AGI, Periódicos, 5/58, El falucho vigía, n. 17, 22-V-1821. Desde los medios afines al piñerismo también se vertieron críticas contra religiosos a los que consideraban enemigos, como el presbítero 
Después de las elecciones de 1820, aparecieron varios escritos en los que se identificaba a los curas como enemigos del régimen constitucional o amenazas para su estabilidad política. Unos eran de autores locales y otros reproducciones de periódicos españoles en los que se daba noticia de los clérigos reaccionarios que actuaban contra el gobierno constitucional. De esa manera, y aprovechando el estado de opinión que existía en los sectores de clases medias y altas de La Habana contra el grupo exaltado de Piñeres, aparecieron varios escritos en los que se cuestionaban el papel de los clérigos en la vida pública:

El buen clérigo precisa/Confesarse, y confesar/Todos los días rezar/Decir misa y oír misa:/Si esto no hace, patentiza/Su mal ejemplo constante/Da que pensar al instante/A toda malicia llena/De que su vida no es buena/Y que del cielo anda errante ${ }^{60}$.

La temática se reflejó también en otras localidades, seguramente como consecuencia de la circulación de contenidos desde La Habana, España y parte de América ${ }^{61}$. La ausencia de conflictos graves y de clérigos que se posicionaran contra la Constitución hace pensar que durante el Trienio existió un consenso contra la injerencia de los religiosos en la vida pública, al menos entre los sectores más ilustrados de la isla, que estaban detrás de la prensa y la opinión pública. En el caso de Santiago de Cuba, el Periódico Nacional publicaba unos días después un escrito dirigido al arzobispo Osés y al jefe político de la provincia para que tomasen previsiones contra el padre Munuera (probablemente un franciscano bien conocido en la ciudad), por el sermón que había impartido el día de San Francisco de 1822, en el cual había regalado al auditorio «con una retahíla de figuras satíricas y expresiones emblemáticas, cubiertas de una buena dosis de política (...) separándose por tanto del texto Evangélico y contrariando las leyes nacionales». Recordaban a las autoridades, además, que «Ya este bendito padre es conocido en Cuba, por aquel famoso sermón del año pasado de 1814 en el que trató de jacobinos y herejes a los padres de la patria» ${ }^{62}$.

Santiago Sánchez Lima, por «abrigar en su casa a los perros chinos escritores bestias y bárbaros del servil, infame, indigno y audaz Navío Arranchador»: AGI, Periódicos 5/23, La corbeta constitucional, n. 2, 5-VII-1822.

60 AGI, Periódicos, 5/58, El falucho vigía, n. 17, 22-V-1821.

61 AgI, Periódicos 5/45, Periódico nacional de Santiago de Cuba, n. 70, 28/09/1822: Reproducen un impreso de Villanueba de la Península titulado: «A los curas y frailes anticonstitucionales» que comienza: «Ministros de guerra, fanatizadores y sublevadores de pueblos, banderizadores de foragidos: yo voy a hablaros».

62 AGI, Periódicos 5/45, Periódico nacional de Santiago de Cuba, n. 73, 09-X-1822. 
A pesar de la aparición de varias publicaciones en las que se representaba a los religiosos como serviles e inconstitucionales, y del consenso en la opinión pública respecto a limitar su intervención en la política, no puede hablarse de un pensamiento anticlerical en Cuba en aquellos años. Los religiosos regulares fueron los que acapararon la mayor parte de las críticas, acusados de improductivos e inconstitucionales, siguiendo la línea general del pensamiento ilustrado y reformista, llegando en alguna ocasión a culparles por los males que afectaban a América desde la conquista. El contexto en que estos escritos salen a la luz es el de la aplicación de ley de monacales, que despertó las ambiciones de sectores de las élites locales y de los propios eclesiásticos seculares sobre los bienes de los conventos. El lenguaje crítico contra los frailes provenía de todo el espectro político de publicaciones y apareció en varias poblaciones de la isla. En la prensa exaltada habanera o piñerista fue donde aparecieron mayor número de escritos en los que se relacionaba a curas y frailes con el servilismo, comparándolos incluso con prusianos y rusos ${ }^{63}$.

El texto más radical de los consultados vio la luz en Puerto Príncipe en septiembre de 1821, cuando casi tres centenares de vecinos presentaron un escrito al ayuntamiento solicitando la clausura de los conventos de la ciudad, por considerarlos perjudiciales. En este caso no se trató de justificar la clausura de los conventos por hallarlos improductivos (que fue el argumento más común). Los promotores del texto señalan a los frailes como conspiradores contra el régimen y les responsabilizan del espíritu partidista que se había instaurado en la ciudad. La aparición de partidos o facciones políticas en pugna fue sin duda la cuestión más candente en los acalorados enfrentamientos que tuvieron lugar allí durante el Trienio:

... desde la cátedra del Espíritu Santo, destinada solamente a predicar la doctrina evangélica, en los parajes más públicos, en tertulias, en sus conversaciones particulares y en cualquiera parte que se hayan, solo tratan de destruir las ideas liberales, de satirizar con inventivas y falsas imputaciones nuestro actual sistema, de propagar máximas ajenas de su instituto, anticonstitucionales y sumamente perniciosas,

63 En julio de 1822 La Corbeta constitucional contiene uno de sus combates imaginarios contra el $\mathrm{Na}$ vío Arranchador (periódico con el que mantiene un cruce de acusaciones constante), al que llama «Navío Servil Arranchador», y al que describe «cargado de rusos, austríacos, prusianos, algunos militares, el padre Vinuesa, otros curas y frailes, todos bajo la comandancia de Tusain». Textos como este, en el que se utiliza la imagen de religiosos serviles como arma arrojadiza para desacreditar a los enemigos políticos son bastante comunes en la mayor parte de las publicaciones. AGI, Periódicos, 5/23, La corbeta constitucional, n. 2, 5-VII-1822. 
cubriéndole con el aparato de un falso celo por la religión, con que logran seducir algunos incautos, y lo que es más notable y digno de la atención de este Ilustre Ayuntamiento, han tratado de introducir la división y la discordia en medio de los habitantes de esta ciudad ${ }^{64}$.

\section{CONCLUSIONES}

A diferencia de la península, donde una parte significativa del clero se posicionó contra el régimen liberal casi desde el momento de aprobación de la Constitución de Cádiz, la Iglesia cubana juró lealtad a la monarquía constitucional y se involucró en la instauración del nuevo régimen político en la isla. El alto clero tuvo una posición cercana al gobierno político, en línea con el pensamiento regalista que caracterizó a los dos prelados de la isla. El obispo habanero, especialmente, demostró sus simpatías con el nuevo régimen apadrinando la enseñanza de las ideas constitucionales y colaborando activamente en la aplicación de leyes que afectaban a los intereses generales de la Iglesia, como la supresión de la Inquisición y la extinción de los monacales.

El bajo clero cubano se caracterizó por su implicación a nivel local en la erección del sistema representativo, no solo como sacerdotes de la liturgia política oficial, sino también en su doble papel de ciudadanos y representantes del nuevo Estado. Sus intervenciones en las juntas parroquiales se dirigieron más a defender sus intereses y los de sus grupos que a velar por las calidades de los electores, tal como estipulaba la Constitución. Las fuentes sobre Cuba apenas muestran interés sobre la comprobación de los criterios de ciudadanía, a pesar de la complejidad de la población. Además de velar por el censo electoral y participar en las juntas parroquiales, la presencia de los curas en las juntas de electores fue muy notoria, especialmente en los ayuntamientos de reciente creación y en los más antiguos del interior de la isla. Desde esa posición, los clérigos se involucraron en las disputas entre los diferentes grupos o facciones políticas locales, de acuerdo con las redes familiares o clientelares a que pertenecieran. No puede decirse, sin embargo, que tal como está documentado en varios territorios de la América continental, los clérigos cubanos controlaran los resultados electorales

64 AHPC, Actas del cabildo de Puerto Príncipe, 10-IX-1821. En el acta se alude a la petición y se reproducen algunos de sus fragmentos, pero no se menciona a los firmantes o promotores del mismo. Es curioso que se dirige la acusación indistintamente, tanto contra los padres mercedarios como contra los franciscanos, como si formaron un mismo cuerpo y tuvieran los mismos intereses. 
a través de la influencia sobre sus feligreses, aunque algunos alcanzaron una clara posición de liderazgo político en sus respectivos territorios.

Las reformas eclesiásticas que se habían llevado a cabo desde principios del siglo XIX por parte de los obispos, especialmente en la diócesis habanera, fueron determinantes para el establecimiento del nuevo orden territorial que preveía la Constitución. La centralidad de las parroquias e iglesias auxiliares erigidas por orden del obispo Espada en la estructuración de un hábitat disperso y en expansión sirvió de referencia para la creación de nuevos ayuntamientos y para la división del territorio en partidos y jurisdicciones electorales. En esas condiciones, los curas rurales se convirtieron en representantes de los intereses locales frente a las cabeceras de partido, diputaciones provinciales y otras autoridades.

La influencia de los clérigos y su participación activa en las elecciones y en la vida pública fue objeto de críticas por parte de facciones o grupos contrarios durante el Trienio Liberal. La mayor parte de estas críticas se dirigieron contra la injerencia o los abusos de los sacerdotes, pero no cuestionaron el papel central que les otorgaba la Constitución en la nueva monarquía. En el caso de los regulares se expresó un amplio consenso entre las fuerzas políticas en considerarlos perjudiciales a la nación por improductivos. En sátiras y décimas políticas los frailes fueron convertidos en símbolos del servilismo, pero salvo alguna excepción, esas alusiones solo fueron armas arrojadizas contra enemigos políticos. En Cuba no puede hablarse de un pensamiento anticlerical en esta época e incluso puede afirmarse que la cuestión religiosa tuvo un papel más bien periférico dentro de los debates políticos. El período que va desde mediados de 1820 hasta finales de 1822 es en el que mayor presencia tuvieron las críticas a los religiosos, espoleadas por las noticias que llegaban desde la península, la movilización del grupo de Piñeres en La Habana y los intereses locales sobre los bienes de las órdenes religiosas. 